\title{
Analisis Kadar Air dan Total Petroleum Hydrocarbon (TPH) dari Proses Bioremediasi Limbah Oli dengan Metode Pengomposan
}

\author{
Husnawati Yahya \\ Prodi Teknik Lingkungan, Fakultas Sains dan Teknologi, \\ Universitas Islam Negeri (UIN) Ar-Raniry, Banda Aceh,Indonesia
}

Koresponden email: husna.bio01@gmail.com

Diterima: 24 Desember 2018

Disetujui: 22 Januari 2019

\begin{abstract}
Engine oil waste is a pollutant that causes environmental pollution and risk for human health. Bioremediation is one of the solutions to solve this problem. In this research, engine oil waste was remediation by composting meth-od. The composting process was conducted in Environmental Engineering laboratory for 35 days. Water content and total petroleum hydrocarbon (TPH) was analyzed in Chemical Engineering laboratory to show the degrada-tion of engine oil waste by combining of liquid fertilizer and compost. The result showed that Total Petroleum Hydrocarbon (TPH) of engine oil waste degradation reached $81 \%$ in sample 8 (by combined $8 \mathrm{~mL}$ of liquid or-ganic fertilizer and $300 \mathrm{~g}$ of compost soil). Sample 12 (by combined $2 \mathrm{~mL}$ of liquid organic fertilizer and $500 \mathrm{~g}$ of compost soil) also showed the same result.
\end{abstract}

Keywords: Bioremediation, TPH, organic fertilizer,compost soil, degradation.

\begin{abstract}
Limbah oli mesin adalah polutan yang menyebabkan polusi lingkungan dan risiko bagi kesehatan manusia. Bioremediasi adalah salah satu solusi untuk menyelesaikan masalah ini. Dalam penelitian ini, limbah oli mesin dipulihkan dengan metode pengomposan. Proses pengomposan dilakukan di laboratorium Teknik Lingkungan selama 35 hari. Kadar air dan hidrokarbon minyak bumi total (TPH) dianalisis di laboratorium Teknik Kimia untuk menunjukkan degradasi limbah oli mesin dengan menggabungkan pupuk cair dan kompos. Hasil penelitian menunjukkan bahwa Total Petroleum Hydrocarbon (TPH) dari degradasi limbah oli mesin mencapai $81 \%$ dalam sampel 8 (dengan menggabungkan 8 mL pupuk organik cair dan 300 g tanah kompos). Sampel 12 (dengan menggabungkan 2 mL pupuk organik cair dan 500 g tanah kompos) juga menunjukkan hasil yang sama.
\end{abstract}

Kata Kunci: Bioremediasi, TPH, Pupuk organik,degradasi, kompos tanah.

\section{Pendahuluan}

Oli merupakan salah satu minyak pelumas yang sering digunakan untuk memperlancar mesin kendaraan (Basuki, 2016). Oli juga termasuk kedalam golongan limbah B3 yang berbahaya bila langsung dibuang ke lingkungan. Limbah oli bekas sering dipakai sebagai bahan bakar (Setyabudhi,2017), dan juga pelarut limbah karet (Nirmala, 2014).

Dampak pencemaran oli bekas bagi lingkungan salah satunya adalah rusaknya komunitas biotik di darat dan di perairan. Selain itu, oli bekas tersebut dapat berbahaya bagi kesehatan manusia karena mengandung senyawa Polycyclic aromatic hydrocarbon (PAH) yang bersifat mutagenic dan karsinogenik (Basuki, 2016).

Salah satu cara yang digunakan dalam mendegradasi limbah oli adalah dengan sistem bioremediasi. Teknik bioremediasi ini pada umumnya menggunakan aktivitas mikroorganisme tertentu dalam proses degradasi limbah. Limbah merupakan salah satu masalah yang terus ada dalam lingkungan manusia. Banyaknya limbah yang telah mencemari lingkungan akan menimbulkan dampak serius bagi lingkungan itu sendiri dan juga bagi kesehatan manusia. Upaya yang perlu segera dilakukan adalah mengelola limbah tersebut agar dapat diminimalisasi dampaknya ataupun dapat dimanfaatkan kembali.

Penelitian ini menggunakan teknik pengomposan pada skala laboratorium. Penambahan pupuk sebagai nutrisi bagi bakteri pendegradasi dan tanah kompos sebagai media pertumbuhan bakteri. Jika pada penelitian sebelumnya banyak yang menggunakan pupuk kimia (urea atau NPK) sebagai nutrisi bagi bakteri, penelitian ini menggunakan pupuk organik cair alami yang terbuat dari bahan-bahan yang ramah lingkungan (seperti: campuran buah-buahan yang telah busuk, bongkol pisang, air cucian beras, air kelapa, dan gula pasir) (Parnata, 2004). Kombinasi antara jerami 
dan mikroorganisme alami yang terdapat dalam tanah kompos juga akan dilakukan pada skala laboratorium dengan menggunakan media pot/polybag.

\section{Metode Penelitian}

\subsection{Alat dan Bahan}

Alat-alat yang digunakan dalam penelitian ini adalah : oven listrik, tanur, cawan petri, desikator, neraca analitik, polybag, $\mathrm{pH}$ indicator, stirrer, shaker, kertas saring, kertas whatman, beker glass, Erlenmeyer, dan peralatan gelas lainnya.

Sedangkan bahan yang digunakan dalam penelitian ini adalah: tanah kompos yang diperoleh dari taman penjualan aneka jenis bunga setempat, jerami yang diperoleh dari para petani setempat, limbah oli bekas dari bengkel AHASS Honda, buah-buahan yang telah busuk, bongkol pisang, air cucian beras, air kelapa dan gula merah/gula pasir, aquades, dan n-heksana.

\subsection{Cara Kerja}

Penelitian ini merupakan pengujian biodegradasi limbah oli dengan kombinasi beberapa konsentrasi pupuk organik cair dan tanah kompos. Proses pengomposan berlangsung selama 35 hari, dilakukan di Laboratorium Teknik Lingkungan, UIN Ar-Raniry. Sedangkan analis kadar air dan TPH dilakukan di Laboratorium Teknik Kimia, Unsyiah. Penelitian ini menggunakan rancangan acak kelompok (RAK), yang terdiri dari 2 faktor yaitu konsentrasi pupuk cair dan tanah kompos.

Teknik yang digunakan adalah metode pengomposan yaitu dengan menggunakan pot/ polybag sebagai media pengomposan skala kecil. Faktor 1 adalah dosis pupuk organik cair $(0 \mathrm{~L}, 2 \mathrm{~mL}, 5$ $\mathrm{mL}, 8 \mathrm{~mL}$, dan $11 \mathrm{~mL}$ ) dan faktor 2 adalah dosis tanah kompos (100 g, 300 g, dan 500 g). Jumlah jerami yang digunakan adalah sebanyak 50 gram untuk setiap perlakuan (Aliyanta et al, 2012). Sedangkan jumlah oli yang dipakai sebanyak $10 \mathrm{~mL}$ (Basuki, 2016) untuk tiap perlakuan. Penelitian ini tidak ada ulangan. Untuk menjaga kelembaban sampel, setiap perlakuan disemprotkan air sebanyak $1 \mathrm{~mL}$ pada awal pengomposan.

Perlakuan kombinasi pupuk organik cair dan tanah kompos terdiri atas:

$\mathrm{P} 1$ : $0 \mathrm{~L}$ pupuk cair $+100 \mathrm{~g}$ tanah kompos + jerami + limbah oli

P2 : $2 \mathrm{~mL}$ pupuk cair $+100 \mathrm{~g}$ tanah kompos + jerami + limbah oli

P3 : $5 \mathrm{~mL}$ pupuk cair $+100 \mathrm{~g}$ tanah kompos + jerami + limbah oli

$\mathrm{P} 4: 8 \mathrm{~mL}$ pupuk cair $+100 \mathrm{~g}$ tanah kompos + jerami + limbah oli
P5 : $11 \mathrm{~mL}$ pupuk cair $+100 \mathrm{~g}$ tanah kompos + jerami + limbah oli

P6 : $0 \mathrm{~L}$ pupuk cair $+300 \mathrm{~g}$ tanah kompos + jerami + limbah oli

P7 : $2 \mathrm{~L}$ pupuk cair $+300 \mathrm{~g}$ tanah kompos + jerami + limbah oli

P8 : $5 \mathrm{~L}$ pupuk cair $+300 \mathrm{~g}$ tanah kompos + jerami + limbah oli

P9 : $8 \mathrm{~L}$ pupuk cair $+300 \mathrm{~g}$ tanah kompos + jerami + limbah oli

P10 : 11 L pupuk cair $+300 \mathrm{~g}$ tanah kompos + jerami + limbah oli

P11 : 0 L pupuk cair $+500 \mathrm{~g}$ tanah kompos + jerami + limbah oli

P12: $2 \mathrm{~L}$ pupuk cair $+500 \mathrm{~g}$ tanah kompos + jerami + limbah oli

P13 : 5 L pupuk cair $+500 \mathrm{~g}$ tanah kompos + jerami + limbah oli

P14: $8 \mathrm{~L}$ pupuk cair $+500 \mathrm{~g}$ tanah kompos + jerami + limbah oli

P15 : 11 L pupuk cair $+500 \mathrm{~g}$ tanah kompos + jerami + limbah oli

\subsection{Pengukuran Kadar Air}

Cawan petri dioven selama satu jam dan dikeringanginkan dalam desikator selama 30 menit. Kemudian dimasukkan $5 \mathrm{~g}$ sampel dalam cawan petri dan dikeringkan dalam oven pada suhu $65-105^{\circ} \mathrm{C}$ selama $24-72$ jam. Selanjutnya sampel kering ditimbang dan kadar air dihitung dengan persamaan Natural Resources Conservation Services (2000) dalam Aliyanta et al. (2012).

Rumus 1 : Pengukuran kadar air

$\%$ Kadar air $=\frac{\text { berat sampel basah-berat } 5 \text { ampel kering }}{\text { berat } s a m p e l ~ b a s a h} \times 100 \%$

\subsection{Pengukuran TPH}

Menurut Ijah dan Upke (1992) dalam Aliyanta et al. (2012), prosedur pengukuran TPH adalah sebagai berikut: diambil 10 gram sampel dan dimasukkan ke dalam Erlenmeyer $250 \mathrm{ml}$, lalu di-tambahkan n-heksana sebanyak $50 \mathrm{ml}$. Kemudian sampel dikocok hingga terlihat minyaknya keluar.

Selanjutnya sampel tadi dimasukkan ke dalam beaker glass dan diuapkan dalam oven pada suhu $70^{\circ} \mathrm{C}$ . Minyak dalam sampel yang diperoleh kemudian ditimbang. Hal ini dilakukan untuk mengetahui jumlah minyak yang tersisa dalam sampel setelah ekstraknya habis menguap. Total degradasi hidrokarbonnya diukur dengan menggunakan rumus di bawah ini:

$\%$ Degradasi $=\frac{T P H_{0}-T P H n}{T P H_{0}} \times 100 \%$ 
Tabel 1. Hasil analisis kadar air

\begin{tabular}{ccc}
\hline Perlakuan & $\begin{array}{c}\text { Berat sampel } \\
\text { basah }\end{array}$ & Berat Sampel Kering \\
\hline P.1 & 54,1 & W2 \\
P.2 & 44,5 & 50,8 \\
P.3 & 52,9 & 41,3 \\
P.4 & 50,2 & 49,7 \\
P.5 & 54,1 & 47,0 \\
P.6 & 22,5 & 50,9 \\
P.7 & 22,8 & 19,8 \\
P.8 & 23,6 & 19,3 \\
P.9 & 23,3 & 20,4 \\
P.10 & 24,3 & 20,4 \\
P.11 & 46 & 22,4 \\
P.12 & 57,8 & 43,6 \\
P.13 & 43,9 & 54,4 \\
P.14 & 39,3 & 40,4 \\
P.15 & 36,6 & 36,2 \\
\hline
\end{tabular}

Dimana : $\mathrm{TPH}_{0}=\mathrm{TPH}$ hari pertama $(\mathrm{gram})$ $\mathrm{TPH}_{\mathrm{n}}=\mathrm{TPH}$ hari ke $-35($ gram $)$

\section{Hasil dan Pembahasan}

\subsection{Kadar Air}

Hasil penelitian menunjukkan bahwa hasil pengukuran kadar air perlakuan mengalami penurunan. Hasilnya dapat dilihat pada Tabel 1.

Pada penelitian ini, jumlah limbah oli yang digunakan adalah sebanyak $10 \mathrm{ml}$. Jumlah limbah oli yang digunakan dalam penelitian ini lebih sedikit dari pada jumlah rata-rata bakteri yang terdapat dalam pupuk kompos dan pupuk cair alami. Udiharto (1995) menjelaskan bahwa kandungan air sangat berpengaruh terhadap aktivitas metabolik bakteri. Hasil penelitian ini menunjukkan bahwa karena limbah oli yang ditambahkan pada tiap perlakuan sedikit, sehingga aktivitas bakteri pengurai juga rendah.

Mikroba yang berasal dari tanah kompos dan juga pupuk cair memperoleh energi dari hasil metabolisme limbah oli. Banyaknya bakteri ini tidak sebanding dengan jumlah limbah oli yang ditampahkan untuk setiap perlakuan. Hal inilah yang menyebabkan penurunan kadar air pada tiap perlakuan. Pada Tabel 1 terlihat bahwa terdapat perbedaan penurunan kadar air pada tiap-tiap perlakuan. Hal ini dapat disebabkan oleh perbedaan penambahan pupuk cair dan tanah kompos. Menurut Mujab (2011), mikroba akan menjadi lebih aktif ketika ditambahkan nutrien. Penambahan nutrien ini menyebabkan mikroba menghasilkan enzim oksigenase yang akan mengoksidasi limbah oli.

Penurunan kadar air yang sangat signifikan terdapat pada perlakuan P6 - P10 (Tabel 1.). Hal ini disebabkan oleh kadar kompos yang ditambahkan, sehingga limbah oli yang semula memiliki kandungan air yang banyak mengalami penurunan kadar air. Sedangkan pada perlakuan P1 - P5 dan P11 - P15 tidak jauh berbeda dimana penurunan kadar air berkisar antara $30 \%-50 \%$. Ini juga dipengaruhi oleh sedikitnya jumlah oli yang dipakai dibandingkan dengan jumlah bakteri pendegradasi. Mujab (2011) juga menambahkan bahwa mikroba memanfaatkan minyak sebagai sumber karbon untuk melakukan metabolisme, sehingga molekul minyak yang melekat pada pori-pori tanah akan terlepas dan terisi oleh air.

\subsection{Total Petroleum Hidrokarbon (TPH)}

Pengukuran TPH dilakukan untuk mengetahui berapa persen rantai hidrokarbon dalam limbah oli yang tersisa setelah mengalami proses pengomposan. Hal ini dilakukan agar senyawa yang berbahaya dalam limbah oli dapat diminimalisasi sehingga aman digunakan sebagai pupuk.

Secara keseluruhan, setiap perlakuan menunjukkan hasil yang berbeda (Tabel 2). Perlakuan 8 dan 12 menunjukkan total degradasi TPH paling tinggi yaitu mencapai $81 \%$. Pada perlakuan 8 , perlakuan terdiri dari 5 liter pupuk cair dan 300 gram tanah kompos

Tabel 2. Hasil analisis kadar TPH

\begin{tabular}{cccc}
\hline Perlakuan & $\begin{array}{c}\text { Berat } \\
\text { Awal (g) }\end{array}$ & $\begin{array}{c}\text { Berat } \\
\text { Akhir (g) }\end{array}$ & $\begin{array}{c}\text { \% } \\
\text { Degradasi }\end{array}$ \\
\hline P.1 & 5,0083 & 3,7463 & 25,20 \\
P.2 & 5,0023 & 2,9302 & 41,42 \\
P.3 & 5,0059 & 2,5365 & 49,33 \\
P.4 & 5,0034 & 2,3889 & 52,25 \\
P.5 & 5,0059 & 1,8609 & 62,83 \\
P.6 & 5,0029 & 2,8159 & 43,71 \\
P.7 & 5,0038 & 2,4735 & 50,57 \\
P.8 & 5,0050 & 0,9423 & $\mathbf{8 1 , 1 7}$ \\
P.9 & 5,0026 & 2,5068 & 49,89 \\
P.10 & 5,0054 & 1,7060 & 65,92 \\
P.11 & 5,0014 & 2,0254 & 59,50 \\
P.12 & 5,0089 & 0,9254 & $\mathbf{8 1 , 5 2}$ \\
P.13 & 5,0071 & 2,0703 & 58,65 \\
P.14 & 5,0062 & 2,9905 & 40,26 \\
P.15 & 5,0008 & 1,8858 & 62,29 \\
\hline
\end{tabular}


dengan total degradasi TPH mencapai 81,17\%. Sedangkan perlakuan 12 terdiri dari 2 liter dan 500 gram tanah kompos dengan total degradasi $\mathrm{TPH}$ mencapai 81,52\% (Tabel 2). Penambahan tanah kompos dapat mempercepat proses degradasi limbah oli oleh mikroba. Sedikitnya oli yang ditambahkan pada tiap perlakuan (hanya $10 \mathrm{~mL}$ ) juga berpengaruh terhadap degradasi TPH limbah oli. Berdasarkan Tabel 2 dapat dilihat bahwa kombinasi pupuk cair dan tanah kompos yang lebih besar belum tentu dapat menurunkan kadar TPH limbah oli. Hal ini dapat terjadi karena perbedaan komposisi bakteri yang terdapat dalam pupuk cair dan kompos. Basuki (2011) menyatakan bahwa kondisi lingkungan sangat berpengaruh bagi kehidupan dan laju metabolisme mikroba pengurai. Seperti yang terlihat dalam Tabel 2 , total TPH yang terdegradasi oleh perlakuan 15 (11 L pupuk cair $+500 \mathrm{~g}$ tanah kompos) sebesar 62,29\%.

Saat bioremediasi terjadi, enzim-enzim yang diproduksi oleh mikroorganisme pengurai akan mendegradasi rantai hidrokarbon limbah oli yang bersifat toksik menjadi senyawa yang bersifat nontoksik (Nirmala,dkk. 2015). Jumlah mikroorganisme yang banyak akan membutuhkan nutrien yang banyak pula. Penambahan limbah oli dengan kadar yang sedikit dalam penelitian ini sangat berpengaruh terhadap jumlah mikroba dan lamanya proses degradasi limbah.

\section{Kesimpulan}

Total degradasi TPH limbah oli dengan menggunakan metode pengomposan mencapai nilai 81\%. Perbedaan total degradasi limbah oli juga dipengaruhi oleh sedikitnya kadar oli yang ditambahkan dalam penelitian yaitu hanya $10 \%$.

\section{Ucapan Terima Kasih}

Terima kasih kepada Kemenag Indonesia yang telah memberikan bantuan penelitian sehingga penelitian ini dapat berjalan dengan lancar. Terima kasih juga kepada Lisa dan Sarah yang telah membantu terlaksananya penelitian ini dengan mengambil data yang berbeda untuk mengamati keefektivan unsur hara dalam bioremediasi limbah oli.

\section{Daftar Pustaka}

Aliyanta, Barokah, Sumarlin, La Ode, \& Mujab, Ahmad Saepul.. Penggunaan Biokompos dalam Bioremediasi Lahan Tercemar Limbah Minyak Bumi. Jurnal Kimia VALENSI, (2012). 2(3).

Basuki, Agus Pindo. Pemanfaatan limbah pelumas oli bengkel otomotif sebagai gemuk lumas (grease) dalam upaya mewujudkan program bengkel bersih.
(2008). Universitas Gadjah Mada.

Basuki, Witono. Biodegradasi Limbah Oli Bekas Oleh Lycinibacillus sphaericus TCP C 2.1. Jurnal Teknologi Lingkungan, 12(2), (2016). 111-119.

Kiswanto, Andi. Perancangan Kompor Dengan Menggunakan Limbah Oli Skala Industri Menengah (2010)..

Mujab, A.S Penggunaan Biokompos dalam Bioremediasi Lahan Tercemar Limbah Minyak Bumi. Skripsi. (2011). UIN Syarif Hidayatullah, Jakarta.

Nghia. N. K. Degradation of Aged Creosote and Diesel Contaminated Soils by Phytoremediation or Biostimulation (nutrients). Master Thesis in Soil Science, 20 credits. (2007). Sveriges lantbruksuniversitet.

Nirmala, Fitria. Pemanfaatan Limbah Karet Ban Dan Plastik Pet (Polyethylene Terephthalate) Menjadi Aspal Sintetis Dengan Oli Bekas Sebagai Pelarut. (2014). Politeknik Negeri Sriwijaya.

Nirmala, Wa Nirmala Wa, Saleh, Asri, \& Novianty, Iin. Kinetika Biodegradasi Limbah Minyak Bumi Menggunakan Biokompos. Al-Kimia, 3(2), (2015). 52-67.

Parnata, Ayub S. Pupuk Organik Cair Aplikasi \& Manfaatnya: AgroMedia. (2004).

Ristiati, Ni Putu. Uji Kemampuan Isolat Bakteri Pendegradasi Minyak Solar Terhadap Limbah Oli Dari Perairan Pelabuhan Celukan Bawang. Paper presented at the Prosiding Seminar Nasional MIPA. (2013).

SEAMEO BIOTROP. Services Laboratory Pengukuran $\mathrm{pH}$ Tanah. Diakses dari http:www. biotrop.org. (2011).

Sopiah, Nida, \& Arifudin, Arifudin. Uji Coba Kinerja Bakteri Karbonoklastik Pada Tanah Tercemar Minyak Bumi Dengan Teknik Landfarming. Jurnal Teknologi Lingkungan, 13(2), (2016).131140.

Susanto, Arif. Pengelolaan Limbah Minyak Pelumas Bengkel Kendaraan Bermotor Konsep Kesadaran Diri. (2014).

Udiharto, M., S. A. Rahayu, A. Haris dan Zulkifliani. Peran bakteri dalam degradasi minyak dan pemanfaatannya dalam penanggulangan minyak bumi buangan.Proceedings Diskusi Ilmiah VIII PPTMGB.Lemigas, (1995).Jakarta 